\title{
10-year follow-up of the Super-Seniors Study: compression of morbidity and genetic factors
}

\author{
Lauren C. Tindale ${ }^{1,2}$, Diane Salema ${ }^{1}$ and Angela R. Brooks-Wilson ${ }^{1,2^{*}}$
}

\begin{abstract}
Background: Super-Seniors are healthy, long-lived individuals who were recruited at age 85 years or older with no history of cancer, cardiovascular disease, diabetes, dementia, or major pulmonary disease. In a 10-year follow-up, we aimed to determine whether surviving Super-Seniors showed compression of morbidity, and to test whether the allele frequencies of longevity-associated variants in APOE and FOXO3 were more extreme in such long-term survivors.
\end{abstract}

Methods: Super-Seniors who survived and were contactable were re-interviewed 10 years after initial characterization. Health and lifestyle were characterized via questionnaire. Geriatric tests including the Timed Up and Go (TUG), Geriatric Depression Scale (GDS), Instrumental Activities of Daily Living (IADL) and the Mini-Mental State Exam (MMSE) were administered, and data were compared to results from on average 10 years earlier. As well, genotype and allele frequencies for SNPs rs7412 and rs429358 in APOE, and rs2802292 in FOXO3 were compared to the frequencies in the original collection of Super-Seniors and mid-life controls.

Results: Of the 480 Super-Seniors recruited from 2004 to 2007, 13 were alive, contactable, and consented to reinterview (mean age $=100.1 \pm 3.3$ ). Eight of these 13 participants (62\%) still met Super-Senior health criteria. Diseases that occurred in late life were cardiovascular (5 of 13; 38\%) and lung disease (1 of 13; 8\%). MMSE and IADL scores declined in the decade between interviews, and GDS and TUG scores increased. The surviving group of centenarians had a higher frequency of APOE and FOXO3 longevity-associated variants even when compared to the original long-lived Super-Senior cohort.

Conclusions: Although physical and mental decline occurred in the decade between interviews, the majority of Super-Seniors re-interviewed still met the original health criteria. These observations are consistent with reports of compression of morbidity at extreme ages, particularly in centenarians. The increased frequency of longevityassociated variants in this small group of survivors is consistent with studies that reported genetics as a larger contributor to longevity in older age groups.

Keywords: Oldest-old, Centenarians, Super-seniors, Healthy aging, Longevity

\footnotetext{
* Correspondence: abrooks-wilson@bcgsc.ca

${ }^{1}$ Canada's Michael Smith Genome Sciences Centre, BC Cancer Research

Centre, 675 West 10th Ave, Vancouver, BC V5Z 1L3, Canada

${ }^{2}$ Biomedical Physiology and Kinesiology, Simon Fraser University, Burnaby,

BC, Canada
}

(c) The Author(s). 2019 Open Access This article is distributed under the terms of the Creative Commons Attribution 4.0 International License (http://creativecommons.org/licenses/by/4.0/), which permits unrestricted use, distribution, and reproduction in any medium, provided you give appropriate credit to the original author(s) and the source, provide a link to the Creative Commons license, and indicate if changes were made. The Creative Commons Public Domain Dedication waiver (http://creativecommons.org/publicdomain/zero/1.0/) applies to the data made available in this article, unless otherwise stated. 


\section{Background}

Maintaining health while aging is important both for individual quality of life as well as costs to health care systems. Compression of morbidity refers to a shorter time between onset of disability and death, and was originally postulated to be due to chronic conditions having a greater capacity to be delayed than survival has to be increased [1]. A correlation between survival age and decreased morbidity has been observed, where older age groups (100-104 years, 105-109 years, and 110-119 years) experienced progressively delayed onset of disease and physical or cognitive impairment [2].

While the overall incidence of chronic conditions has been increasing in recent decades [3, 4], compression of morbidity has been observed in long-lived individuals [5-8]. As studies of younger groups (e.g., 51-61 years) [4] did not reveal compression of morbidity, the reduction in years of disease may be limited to the high end of the human life span.

The Super-Seniors were collected as a phenotypically healthy oldest-old group in which to study genetic factors associated with healthy aging $[9,10]$. Super-Seniors are individuals aged 85 years and older who reported never being diagnosed with cancer, cardiovascular disease (CVD), diabetes, dementia, or major pulmonary disease. Study controls are a population-based comparison group of mid-life individuals who resemble a genetic proxy group for the birth cohort of the Super-Seniors [10]. The initial collection and characterization of 480 Super-Seniors took place from 2004 to 2007 (Phase 1), with an additional and ongoing collection initiated in 2014 (Phase 2).

Approximately 10 years after the Phase 1 collection of Super-Seniors, we attempted to re-contact and re-interview surviving Super-Seniors. Participants still living would be in their late nineties or 100 or more, and we hypothesized that such individuals would have retained much of their health due to compression of morbidity.

\section{Methods}

Research ethics board approval was received from the joint Clinical Research Ethics Board (REB) of BC Cancer and the University of British Columbia and from the REB of Simon Fraser University. All subjects gave written informed consent.

Phase 1 collection of Super-Seniors in 2004-2007 [10] did not include plans to follow participants longitudinally, so in 2010, Super-Seniors were mailed a letter requesting permission to re-contact them for future research. In 2016-17, contactable and interested Super-Seniors were invited for re-interview (Additional file 1: Figure S1).

Super-Seniors were visited in their homes where they were asked personal and family medical history questions, and asked to perform geriatric tests as per their first interview. The Mini-Mental State Exam (MMSE) [11], Instrumental Activities of Daily Living (IADL) [12], Geriatric Depression Scale (GDS) [13], and Timed Up and Go (TUG) [14] were measured and compared to data from Phase 1 Super-Seniors collected approximately 10 years previously. Differences in scores were analyzed in one-tailed paired t-tests with the expectation that MMSE and IADL score would decrease with age, and that GDS and TUG scores would increase. BMI, HR, and BP were compared using two-tailed paired t-tests.

Genotype and allele frequencies for SNPs rs7412 and rs429358 in APOE, and rs2802292 in FOXO3 were compared to the frequencies in the original Phase 1 Super-Seniors and mid-life controls. Genotypes for these select variants were extracted from data previously described [15]. Statistical analysis was done using R 3.2.2 and JMP 13.

\section{Results}

In 2010, we mailed 480 Super-Seniors and an additional 17 borderline phenotype individuals from Phase 1, excluding 9 for whom the study had been notified of their death. Twenty-six were reported deceased by relatives, 30 declined (5/30 indicated they were "too sick"), 92 were unable to be contacted (mail was returned to sender), 246 did not respond, and 94 agreed to be re-contacted (Additional file 1).

In 2016, we searched for online obituaries and notices of death, and sent another letter requesting permission for re-contact to 139 previous non-responders. By 2016, an additional 107 Super-Seniors were determined to be deceased through online records or reported to the study by family members. Of the 138 Super-Seniors mailed in 2016, 8 were reported deceased, 7 declined (3/ 7 indicated they were "too sick"), 26 were unable to be contacted, 89 did not respond, and 9 agreed to be re-contacted.

Twenty-eight Super-Seniors were invited for interview. Of those, 13 accepted and completed the re-interview; 2 declined, 10 could not be reached, 1 died, and 2 were reported by relatives to be too ill to be interviewed. The 13 Super-Seniors re-interviewed in 2017 included 10 women and 3 men aged 96-106 (mean =100.1, SD = 3.3), who were all of European ancestry.

The two Super-Seniors who were too ill to be interviewed included a 100-year-old woman reported by a family member to be confused much of the time, not doing very well, and feeling sick and tired. The other was a 106-year-old woman reported by a family member to be bedridden and mostly non-responsive. Deterioration reportedly took place around age 100-101 when she began suffering episodes of dementia. Other than dementia, she had no health problems and was very mobile until age 103. 
Re-interviews took place 9.3-12.1 years $($ mean $=10.9$, $\mathrm{SD}=0.9$ ) after the initial interviews (Additional file 2). Of the 13 Super-Seniors who were re-interviewed, 8 still met the health criteria for being a Super-Senior, 5 women and all 3 of the men. Of the 5 Super-Seniors who did not meet the criteria for enrollment at the time of their re-interview in 2017, all had developed CVD: two had strokes (at ages 97 and 100, respectively), two had heart conditions (mitral valve issue [age unknown] and pacemaker [at age 99]), and one who was interviewed at age 96 had a minor heart attack, minor strokes, and COPD.

Of the 13 Super-Seniors re-interviewed, 6 were never smokers and the remaining 7 had quit. The quitters smoked between 5 and 51 years ( mean $=29.7, \mathrm{SD}=16.0$ ). Of note, the individual who had COPD was a housewife who never smoked.

Descriptive statistics and geriatric test scores are shown in Table 1 and Fig. 1. MMSE mean scores declined from $28.7(\mathrm{SD}=1.4)$ to $23.8(\mathrm{SD}=4.2)$ points out of a possible 30, a mean decline of 4.9 points $(t=-4.5$, $P=0.00036)$. IADL scores declined from $22.3(\mathrm{SD}=1.5)$ to $15.6(\mathrm{SD}=6.1)$ out of a possible 23 points, a mean decline of 6.7 points $(t=-3.7, P=0.0016)$. GDS scores increased from $0.5(\mathrm{SD}=1.0)$ to $2.2(\mathrm{SD}=2.5)$, a mean difference of 1.7 points $(t=2.6, P=0.011)$. TUG scores increased from $9.8(\mathrm{SD}=2.1)$ to $32.0(28.0)$ seconds, a mean difference of $22.2 \mathrm{~s}(\mathrm{t}=2.9, P=0.0070)$. Among the 9 individuals who did not use a walker as an aid, the mean TUG time was $17.9 \mathrm{~s}(\mathrm{SD}=5.3)$.
There was no significant difference in BMI, heart rate, or blood pressure (BP) between the two interviews. Eight participants were taking BP medication at the time of both interviews, 4 were not taking any BP medication at either interview, and one man had discontinued taking BP medication by the time of the second interview.

Genotyping in re-interviewed Super-Seniors was not available for one participant in $A P O E$ and two participants in FOXO3. Genotype counts and minor allele frequency (MAF) values are shown in Table 2. Genotyping of Phase 1 Super-Seniors and controls was used for comparison [15].

\section{Discussion}

We attempted to re-contact Super-Seniors 9-12 years after they were enrolled. As expected for an older group, even one as healthy as the Super-Seniors, most participants had passed away within this time frame. We could confirm that at least 17 of the original 480 Super-Seniors were still living.

Eight of the 13 individuals re-interviewed in 2017 (54\%) still met the criteria for being a Super-Senior; among the individuals who no longer met the Super-Senior criteria, most had developed their health problems in the previous 3 years. The most common diseases in the group were CVD ( 5 of $13 ; 38 \%$ ), and lung disease ( 1 of $13 ; 8 \%$ ). According to the US National Center for Health Statistics from 2012 to 2013, 29.8\% of Americans aged 65 years and older reported having heart disease, and $18.4 \%$ reported having cancer [3]. As well,

Table 1 Characteristics of Super-Seniors at two interviews approximately 10 years apart

\begin{tabular}{|c|c|c|c|c|}
\hline \multirow[b]{3}{*}{ Year } & \multirow{3}{*}{$\begin{array}{l}\text { Super-Seniors } \\
\text { Study } \\
2004-2007\end{array}$} & \multicolumn{2}{|l|}{ Re-contacts } & \multirow{3}{*}{$\begin{array}{l}P \text {-value } \\
\text { 1st and 2nd } \\
\text { interviews }\end{array}$} \\
\hline & & \multirow{2}{*}{$\begin{array}{l}\text { First Interview } \\
\text { 2004-2007 }\end{array}$} & \multirow{2}{*}{$\begin{array}{l}\text { Second Interview } \\
\text { 2016-2017 }\end{array}$} & \\
\hline & & & & \\
\hline $\mathrm{N}$ & 480 & & & \\
\hline Male & 155 & & & \\
\hline Female & 325 & & & \\
\hline Age mean (SD) years & $88.5(2.9)$ & $89.3(2.7)$ & $100.1(3.3)$ & \\
\hline Age range & $85-105$ & $85-94$ & $96-106$ & \\
\hline Years between interviews (SD) & - & & & \\
\hline BMI mean (SD) kg/m² & $24.5(3.9)$ & $25.8(4.0)$ & $23.4(3.9)^{\mathrm{a}}$ & 0.071 \\
\hline BP mean systolic (SD) mmHg & $152(21)^{a}$ & $142(16)^{a}$ & $120(35)$ & 0.077 \\
\hline BP mean diastolic (SD) mmHg & $78(11)^{a}$ & $72(9)^{a}$ & $72(10)$ & 0.980 \\
\hline Heart rate (SD) beats per min & $70(11)^{\mathrm{a}}$ & $67(9)^{a}$ & $74(11)$ & 0.120 \\
\hline MMSE mean (SD) & $28.3(1.7)$ & $28.7(1.4)$ & $23.8(4.2)$ & $<0.001$ \\
\hline IADL mean (SD) & $21.4(3.5)$ & $22.3(1.5)$ & $15.6(6.1)$ & 0.002 \\
\hline GDS mean (SD) & $1.5(1.8)$ & $0.5(1.0)$ & $2.2(2.5)$ & 0.011 \\
\hline TUG mean (SD) seconds & $12.3(4.3)$ & $9.8(2.1)$ & $32.0(28.0)$ & 0.007 \\
\hline
\end{tabular}

${ }^{\mathrm{a} B l o o d}$ pressure and heart rate were not available for all initial interviews. Super-Seniors Study blood pressure $n=298$, heart rate $n=290$. Re-contacts first interview blood pressure $n=12$, heart rate $n=12$. Re-contacts second interview BMI $n=12$ 

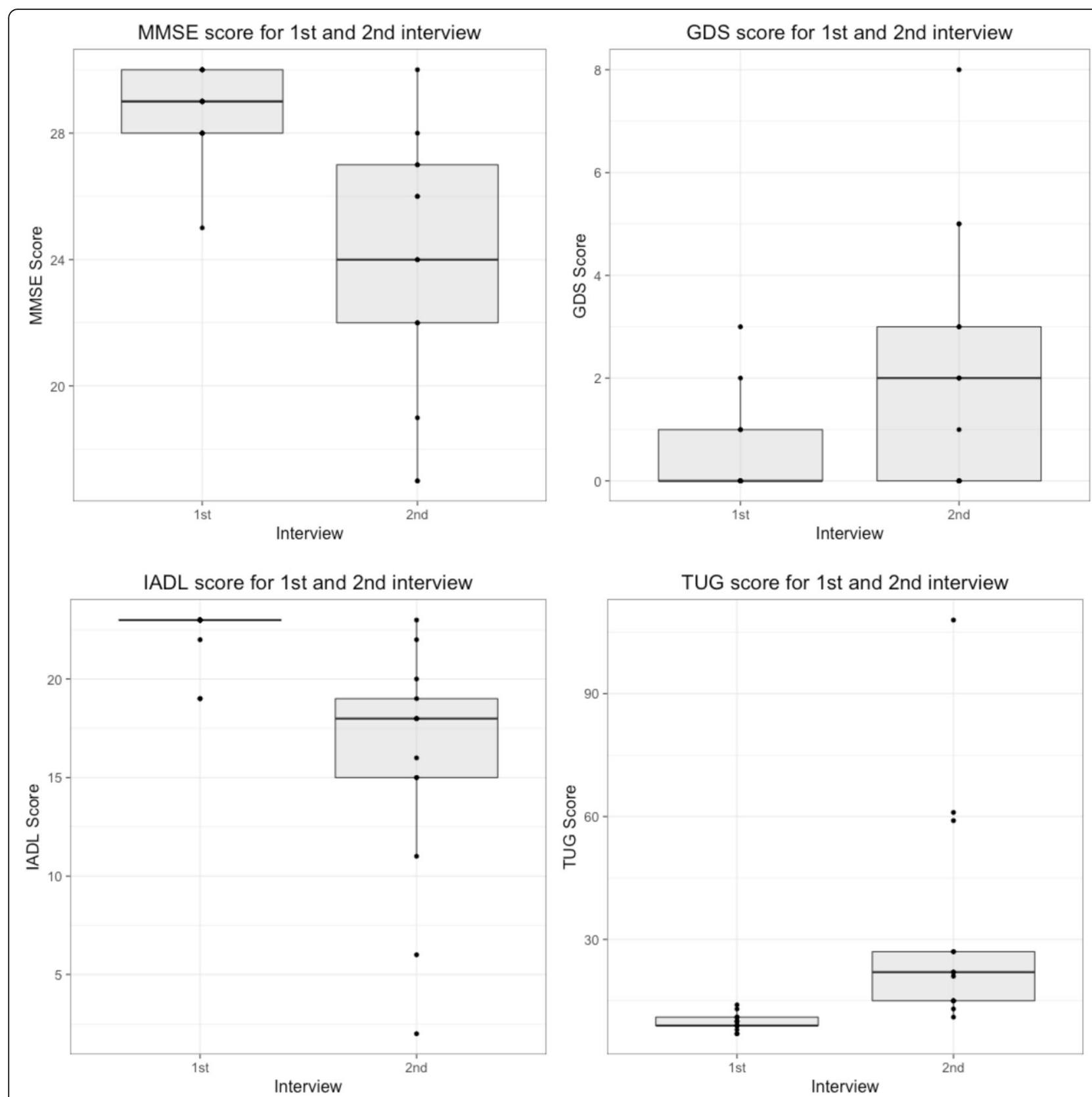

Fig. 1 Super-Senior geriatric test scores at the first and second interviews approximately 10 years apart. MMSE = Mini-Mental State Exam, GDS= Geriatric Depression Scale, IADL = Instrumental Activities of Daily Living, TUG = Timed Up and Go

in a cohort of men born in 1913 and followed to age 100, CVD was the most common cause of death after the 80 years of age [16].

Although we cannot compare relative morbidity time between groups, our observations that $8 / 13$ of the survivors were still "Super", and that the $5 / 13$ with chronic diseases developed them in their late 90 s or early $100 \mathrm{~s}$, these observations suggest that compression of morbidity is occurring in these individuals. Compression of morbidity has been suggested in other studies of long-lived people including the New England Centenarian Study, where they found that between nonagenarians, centenarians, semicentenarians (105-109 years), and supercentenarians (110-119 years), there was a later onset of major age-related diseases as the age group increased [2]. As well, among 15 Okinawa supercentenarians (age at death 110-112) it was found that they had delayed clinically apparent diseases until very late in life, with $83 \%$ not reporting clinically apparent disease until 105 years or later [17]. 
Table 2 Genotype comparison between Super-Senior survivors, and the original Phase 1 collection of Super-Seniors and controls

\begin{tabular}{|c|c|c|c|c|c|c|}
\hline & Re-interview & $(n=13)$ & All Super-Se & & Controls $(n$ & \\
\hline & Genotypes & MAF & Genotypes & MAF & Genotypes & $\overline{M A F}$ \\
\hline APOE rs 7412 & $\begin{array}{l}T T \times 1 \\
T C \times 1 \\
C C \times 10\end{array}$ & 0.125 & $\begin{array}{l}T \times 6 \\
T C \times 69 \\
C C \times 363\end{array}$ & 0.092 & $\begin{array}{l}T \times 3 \\
T C \times 57 \\
C C \times 352\end{array}$ & 0.076 \\
\hline APOE rs429358 & $\begin{array}{l}C C \times 0 \\
C T \times 2 \\
\pi \times 10\end{array}$ & 0.083 & $\begin{array}{l}C C \times 4 \\
C T \times 84 \\
\Pi \times 350\end{array}$ & 0.105 & $\begin{array}{l}C C \times 10 \\
C T \times 110 \\
\pi \times 293\end{array}$ & 0.157 \\
\hline FOXO3 rs 2802292 & $\begin{array}{l}\mathrm{GG} \times 0 \\
\mathrm{GT} \times 9 \\
T T \times 2\end{array}$ & 0.409 & $\begin{array}{l}\mathrm{GG} \times 55 \\
\mathrm{GT} \times 226 \\
\pi \times 162\end{array}$ & 0.379 & $\begin{array}{l}\mathrm{GG} \times 47 \\
\mathrm{GT} \times 189 \\
\pi \times 166\end{array}$ & 0.352 \\
\hline
\end{tabular}

MAF minor allele frequency

A German health insurance study also found that there was a lower prevalence of comorbidities among those who died as centenarians than those who died in their 80s [8]. Likewise, while 8 Super-Seniors were still disease free, 5 had one disease, and only one individual had co-morbidities.

We compared the current geriatric test scores of the Super-Seniors to their initial interview scores. MMSE and IADL scores declined in the decade between interviews, while GDS and TUG scores increased. For all four tests, the standard deviation increased from the first to second interviews indicating that there was a wider range of physical and cognitive function as the surviving participants aged.

Mean MMSE scores decreased from 28.7 to 23.8 points. Although this is a test of cognitive function, at least a portion of the decreased score was due to visual and/or hearing impairment, which affected the participant's ability to answer some questions. At the time of the second interview, two individuals were legally blind, another was unable to see the images, and three were hard of hearing. Vision impairment for these individuals was not noted at the time of the first interview. It is worth noting however, that the one perfect score among the re-interviews was by a 102-year-old woman with macular degeneration. The traditional cut-off score for being "normal" and without cognitive impairment is 24 , however a study of highly educated Caucasians found that a cut-off of 24 resulted in a moderate sensitivity (0.66) and very high specificity (0.99), whereas a cut-off score of 27 achieved a balance between sensitivity (0.89) and specificity (0.91) [18]. At the second interview, the Super-Seniors mean score almost meets the traditional 24-point cut-off. Individually however, the range of scores decreased from 25 to 30 points to $17-30$ points indicating that at while some Super-Seniors have retained their cognitive function, others are experiencing increasing impairment.

All geriatric scores declined with age, with the second interview showing that the Super-Seniors had a mean higher depression score, decreased mobility, and were performing fewer daily tasks as measured by the IADL. Their
GDS score, however, was still a mean of 2.2 points, below the value of $\geq 5$ that has been indicated as an appropriate cut-off score for depression [19]. As well, although the TUG time increased from a mean of 9.8 to $32.0 \mathrm{~s}, 4$ individuals used a walker as a mobility aid and one used a cane. The mean TUG time for individuals without a walker was $17.9 \mathrm{~s}$. Although there is no specific standard for TUG time, it has been found that physical fitness indicators such as the TUG are associated with successful aging [20]. It has also been suggested that among adults 65 years and older with a similar disease burden, those who were more physically vigorous experienced compression of morbidity and lived longer [21]. A decreased IADL score indicates that they are performing fewer tasks independently; however, and in a study of individuals 90 years and older, regularly needing help was found to be a significant predictor of mortality [22].

The Okinawa centenarian study found that both BMI and BP decreased with age as individuals transitioned from centenarians to supercentenarians [17]. Longitudinally, when they followed individuals from age groups 99103 years, to $104-107$ years, to $108-111$ years, their BMI decreased from 21.47 , to 18.81 , to 17.43 , respectively. As well, their BP (systolic/diastolic) decreased from 142/74 $\mathrm{mmHg}$, to $128 / 70 \mathrm{mmHg}$, to $119 / 64 \mathrm{mmHg}$. Similarly, following the Super-Seniors from ages 85-94 years, to 96106 years, we saw a non-significant decrease in BMI from $25.8(\mathrm{SD}=4.0)$ to $23.4(\mathrm{SD}=3.9)$. Systolic $\mathrm{BP}$ of the Super-Seniors decreased from $142 \mathrm{mmHg}(\mathrm{SD}=16)$ to $120 \mathrm{mmHg}(\mathrm{SD}=35)$ and diastolic BP remained the same at $72 \mathrm{mmHg}(\mathrm{SD}=9)$ and $72 \mathrm{mmHg}(\mathrm{SD}=10)$. Interestingly, the re-interviewed Super-Seniors had lower values at their initial interviews for both their systolic and diastolic BP than the mean of the overall Phase 1 Super-Seniors cohort, 152/78 mmHg (Table 1). Both the values and the decline exhibited in Super-Seniors are consistent with what was observed in the Okinawa study.

$A P O E$ and FOXO3 are the two loci most consistently associated with longevity, reviewed by: [23-25]. APOE has been found in genome-wide scans and cohort studies of longevity; the minor allele of rs7412 is sometimes 
associated with longevity, and the minor allele of rs429358 is reliably associated with increased mortality [26-31]. Together these two variants determine APOE2/ 3/4 haplotypes. At rs7412, the re-interviewed Super-Seniors had a MAF 0.125, compared to MAF 0.092 in all Phase 1 Super-Seniors, and MAF 0.076 in mid-life controls. At rs429358, the re-interviewed Super-Seniors had MAF 0.083, compared to 0.105 in all Super-Seniors, and 0.157 in controls. This demonstrates that among these elite survivors, Super-Seniors who survived another $\sim 10$ years, there appears to be a slightly higher frequency of the favorable longevity allele of rs7412, and a lower frequency of the deleterious mortality and AD-related allele of rs429358, even when compared to the original group of Phase 1 Super-Seniors.

In FOXO3, the $\mathrm{G}$ allele of rs 2802292 has been associated with longevity [32]. $81.2 \%$ re-interviewed Super-Seniors carried at least one G allele, compared to $63.4 \%$ in all Phase 1 Super-Seniors and $58.7 \%$ of controls. Previously we did not find an association of rs2802292 with the Super-Senior phenotype, compared to mid-life controls, but we do see an apparent enrichment among this small group of survivors. This possible association may be stronger at more advanced ages, or it could be an artifact of the very small sample size.

It is important to note that this study is limited by very small sample size. Observations made in this small group of individuals may not be typical of centenarians in general. Partially contributing to this low number, however, is the fact that the majority of Super-Seniors were either not contactable or did not respond and, while most will have passed away, we do not know the exact number. As well, although the average age at recruitment was 88.5 years, some Super-Seniors were already in or near their $100 \mathrm{~s}$ at the time of initial recruitment and would therefore be less likely to be alive 10 years later. Given that the average lifespan for the Super-Seniors birth cohort (mean birth year 1916) was approximately 57 years, the 13 Super-Seniors who were re-interviewed represent a small but elite group who delayed disease onset until very late in life, and possibly exhibit compression of morbidity.

\section{Conclusions}

Although physical and mental decline occurred in the decade between interviews, the majority of Super-Seniors re-interviewed still met the original health criteria. These observations are consistent with reports of compression of morbidity at extreme ages, particularly in centenarians $[5,7,8]$. The increased frequency of longevity-associated variants in this small group of survivors is consistent with studies that reported genetics as a larger contributor to longevity in older age groups [33, 34].

\section{Additional files}

Additional file 1: Follow-up of participants in the Super-Seniors Study flow chart. (PDF $39 \mathrm{~kb}$ )

Additional file 2: Study dataset. (XLSX $38 \mathrm{~kb}$ )

\section{Abbreviations}

BMI: Body mass index; BP: Blood pressure; COPD: Chronic obstructive pulmonary disease; CVD: Cardiovascular disease; GDS: Geriatric Depression Scale; IADL: Instrumental Activities of Daily Living; MAF: Minor allele frequency; MMSE: Mini-Mental State Exam; REB: Research ethics board; SD: Standard deviation; SNP: Single nucleotide polymorphism; TUG: Timed up and go

\section{Acknowledgements}

We thank Monique Sekhon and Olivia Aguiar who conducted the second interviews.

\section{Funding}

This work was carried out with funding from the Lotte and John Hecht Memorial Foundation. LCT was supported by a Doctoral Award from the Canadian Institutes for Health Research. The funding agencies did not have any role in the design of the study, collection, analysis, interpretation of data, and in writing the manuscript.

\section{Availability of data and materials}

The datasets used and analysed during the current study available from the corresponding author on reasonable request.

\section{Authors' contributions}

LCT: study concept and design, analysis and interpretation of data, drafting and final approval of manuscript. DS: acquisition of subjects and data, revision and final approval of manuscript. ARBW: study concept and design, revision and final approval of manuscript. All authors read and approved the manuscript.

\section{Ethics approval and consent to participate}

Research ethics board approval was received from the joint Clinical Research Ethics Board (REB) of BC Cancer and the University of British Columbia and from the REB of Simon Fraser University. All subjects gave written informed consent.

\section{Consent for publication}

Not applicable.

\section{Competing interests}

The authors declare that they have no competing interests.

\section{Publisher's Note}

Springer Nature remains neutral with regard to jurisdictional claims in published maps and institutional affiliations.

Received: 2 August 2018 Accepted: 19 February 2019 Published online: 28 February 2019

\section{References}

1. Aging FJF, Death N. The compression of morbidity. N Engl J Med. 1980; 303(3):245-50

2. Andersen SL, Sebastiani P, Dworkis DA, Feldman L, Perls $\pi$. Health span approximates life span among many supercentenarians: compression of morbidity at the approximate limit of life span. J Gerontol A Biol Sci Med Sci. 2012;67(4):395-405.

3. National Center for Health Statistics (US). Health, United States, 2014: With Special Feature on Adults Aged 55-64. Hyattsville (MD): National Center for Health Statistics (US). 2015; Report No.: 2015-1232. https://www.ncbi.nlm. nih.gov/books/NBK45497/.

4. Beltran-Sanchez $H$, Jimenez MP, Subramanian SV. Assessing morbidity compression in two cohorts from the health and retirement study. J Epidemiol Community Health. 2016;70(10):1011-6. 
5. Ismail K, Nussbaum L, Sebastiani P, Andersen S, Perls T, Barzilai N, et al. Compression of morbidity is observed across cohorts with exceptional longevity. J Am Geriatr Soc. 2016;64(8):1583-91.

6. Christensen K, McGue M, Petersen I, Jeune B, Vaupel JW. Exceptional longevity does not result in excessive levels of disability. Proc Natl Acad Sci U S A. 2008;105(36):13274-9.

7. Kheirbek RE, Fokar A, Shara N, Bell-Wilson LK, Moore HJ, Olsen E, et al. Characteristics and incidence of chronic illness in community-dwelling predominantly male U.S. veteran centenarians. J Am Geriatr Soc. 2017;65(9): 2100-6.

8. Gellert P, von Berenberg P, Oedekoven M, Klemt M, Zwillich C, Horter S, et al. Centenarians differ in their comorbidity trends during the 6 years before Death compared to individuals who died in their 80 s or $90 \mathrm{~s}$. J Gerontol A Biol Sci Med Sci. 2018;73(10):1357-62.

9. Halaschek-Wiener J, Amirabbasi-Beik M, Monfared N, Pieczyk M, Sailer C, Kollar A, et al. Genetic variation in healthy oldest-old. PLoS One. 2009; 4(8):e6641.

10. Halaschek-Wiener J, Tindale LC, Collins JA, Leach S, McManus B, Madden K, et al. The super-seniors study: phenotypic characterization of a healthy $85+$ population. PLoS One. 2018;13(5):e0197578.

11. Folstein MF, Folstein SE, McHugh PR. "Mini-mental state". A practical method for grading the cognitive state of patients for the clinician. J Psychiatr Res. 1975;12(3):189-98.

12. Lawton MP, Brody EM. Assessment of older people: self-maintaining and instrumental activities of daily living. Gerontologist. 1969;9(3):179-86.

13. Sheikh JI, Yesavage JA. Geriatric depression scale (GDS) recent evidence and development of a shorter version. Clin Gerontol. 1986;5:165-73.

14. Podsiadlo D, Richardson S. The timed "up \& go": a test of basic functional mobility for frail elderly persons. J Am Geriatr Soc. 1991;36(2):142-8.

15. Tindale LC, Leach S, Spinelli JJ, Lipid B-WA. Alzheimer's disease genes associated with healthy aging and longevity in healthy oldest-old. Oncotarget. 2017:8(13):20612-21.

16. Wilhelmsen L, Dellborg M, Welin L, Svardsudd K. Men born in 1913 followed to age 100 years. Scand Cardiovasc J. 2015;49(1):45-8.

17. Willcox DC, Willcox BJ, Wang N, He Q, Rosenbaum M, Suzuki M. Life at the extreme limit: phenotypic characteristics of supercentenarians in Okinawa. J Gerontol A Biol Sci Med Sci. 2008;63(11):1201-8.

18. O'Bryant SE, Humphreys JD, Smith GE, Ivnik RJ, Graff-Radford NR, Petersen $\mathrm{RC}$, et al. Detecting dementia with the mini-mental state examination in highly educated individuals. Arch Neurol. 2008;65(7):963-7.

19. Marc LG, Raue PJ, Bruce ML. Screening performance of the 15-item geriatric depression scale in a diverse elderly home care population. Am J Geriatr Psychiatry. 2008;16(11):914-21.

20. Lin PS, Hsieh CC, Cheng HS, Tseng TJ, Su SC. Association between physical fitness and successful Aging in Taiwanese older adults. PLoS One. 2016; 11(3):e0150389.

21. Sanders JL, Arnold AM, Hirsch CH, Thielke SM, Kim D, Mukamal KJ, et al. Effects of disease burden and functional adaptation on morbidity and mortality on older adults. J Am Geriatr Soc. 2016;64(6):1242-9.

22. Jylhä M, Hervonen A. Functional status and need of help among people aged 90 or over: a mailed survey with a total home-dwelling population. Scand J Public Health. 1999;27(2):106-11.

23. Brooks-Wilson AR. Genetics of healthy aging and longevity. Hum Genet. 2013;132(12):1323-38.

24. Christensen K, Johnson TE, Vaupel JW. The quest for genetic determinants of human longevity: challenges and insights. Nat Rev Genet. 2006;7(6):436-48.

25. Wheeler HE, Kim SK. Genetics and genomics of human ageing. Philos Trans R Soc Lond Ser B Biol Sci. 2011;366(1561):43-50.

26. Schupf N, Barral S, Perls T, Newman A, Christensen K, Thyagarajan B, et al. Apolipoprotein E and familial longevity. Neurobiol Aging. 2013;34(4): 1287-91.

27. Frisoni GB, Louhija J, Geroldi C, Trabucchi M. Longevity and the e2 allele of apolipoprotein E: the Finnish centenarians study. J Gerontol A Biol Sci Med Sci. 2001;56(2):M75-8.

28. Ryu S, Atzmon G, Barzilai N, Raghavachari N, Suh Y. Genetic landscape of APOE in human longevity revealed by high-throughput sequencing. Mech Ageing Dev. 2016;155:7-9.

29. Schächter F, Faure-Delanef L, Guénot F, Rouger H, Froguel P, Lesueur-Ginot $L$, et al. Genetic associations with human longevity at the APOE and ACE loci. Nat Genet. 1994;6(1):29-32.
30. Rea IM, Mc Dowell I, McMaster D, Smye M, Stout R, Evans A, et al. Apolipoprotein E alleles in nonagenarian subjects in the BELFAST elderly longitudinal free-living ageing study (BELFAST). Mech Ageing Dev. 2001; 122(13):1367-72.

31. Bennati E, Murphy A, Cambien F, Whitehead AS, Archbold GP, Young IS, et al. BELFAST centenarians: a case of optimised cardiovascular risk? Curr Pharm Des. 2010;16(7):789-95.

32. Willcox BJ, Donlon TA, He Q, Chen R, Grove JS, Yano K, et al. FOXO3A genotype is strongly associated with human longevity. Proc Natl Acad Sci U S A. 2008;105(37):13987-92.

33. Murabito JM, Yuan R, Lunetta KL. The search for longevity and healthy aging genes: insights from epidemiological studies and samples of longlived individuals. J Gerontol A Biol Sci Med Sci. 2012;67(5):470-9.

34. Newman AB, Murabito JM. The epidemiology of longevity and exceptional survival. Epidemiol Rev. 2013:35:181-97.
Ready to submit your research? Choose BMC and benefit from:

- fast, convenient online submission

- thorough peer review by experienced researchers in your field

- rapid publication on acceptance

- support for research data, including large and complex data types

- gold Open Access which fosters wider collaboration and increased citations

- maximum visibility for your research: over $100 \mathrm{M}$ website views per year

At BMC, research is always in progress.

Learn more biomedcentral.com/submissions 